\title{
ASSOCIATION OF HANDGRIP STRENGTH AND MUSCLE MASS WITH DEPENDENCY IN (INSTRUMENTAL) ACTIVITIES OF DAILY LIVING IN HOSPITALIZED OLDER ADULTS - THE EMPOWER STUDY
}

\author{
C.G.M. MESKERS ${ }^{1,2, *}$, E.M. REIJNIERSE ${ }^{3, *}$, S.T. NUMANS ${ }^{4}$, R.C. KRUIZINGA ${ }^{4}$, V.D. PIERIK ${ }^{4}$, \\ J.M. VAN ANCUM ${ }^{1}$, M. SLEE-VALENTIJN ${ }^{5}$, K. SCHEERMAN ${ }^{4}$, S. VERLAAN ${ }^{4}$, A.B. MAIER ${ }^{1,3, *}$ \\ 1. Department of Human Movement Sciences, @ AgeAmsterdam, Amsterdam Movement Sciences, Amsterdam, The Netherlands; 2. Department of Rehabilitation Medicine, Amsterdam \\ UMC, Amsterdam, The Netherlands; 3. Department of Medicine and Aged Care, @ AgeMelbourne, Royal Melbourne Hospital, University of Melbourne, Melbourne, Australia; \\ 4. Department of Internal Medicine, Section of Gerontology and Geriatrics, Amsterdam UMC, Amsterdam, The Netherlands; 5. Center of Excellence in Geriatric Rehabilitation, Cordaan, \\ Amsterdam, The Netherlands. *authors contributed equally. Corresponding author: Prof. Andrea B. Maier, @ Age, Department of Human Movement Sciences, Amsterdam, Movement \\ Sciences, Van der Boechorststraat 9, 1081 BT Amsterdam, Amsterdam, The Netherlands, P: +31 20 5988888, E: a.b.maier@vu.nl
}

\begin{abstract}
Objectives: Handgrip strength (HGS) and muscle mass are strong predictors for dependency in Activities of Daily Living (ADL) and Instrumental Activities of Daily Living (IADL) in community dwelling older adults. Whether this also applies to older hospitalized patients is yet unknown. We studied the association between HGS and muscle mass with ADL and IADL dependency at admission and change of ADL and IADL dependency at three months after discharge in older hospitalized patients. Design: Observational longitudinal inception cohort (EMPOWER) including 378 patients aged 70 years and older. Setting: Four different clinical wards of a university teaching hospital, The Netherlands. Measurements: HGS and muscle mass were measured within 48 hours after admission using hand dynamometry and Bio-electrical Impedance Analysis respectively. ADL dependency was assessed using the Katz score (0-6 points) and IADL dependency using the Lawton and Brody score (0-8 points) within 48 hours after admission and three months after discharge. Results: At admission, lower HGS was associated with ADL dependency in both males and females. Lower muscle mass was associated with ADL dependency in males. Lower HGS was associated with IADL dependency, but only in males. Lower HGS at admission in males was associated with an increase in ADL dependency three months after discharge. Conclusion: In hospitalized older patients, HGS is associated with ADL and IADL and muscle mass measures with ADL in male patients only. HGS should be explored as predictive marker for outcome of hospitalized older patients after discharge.
\end{abstract}

Keywords: Muscles, muscle mass, muscle strength, handgrip strength, activities of daily living, hospitalization, outcome assessment, aged.

\section{Introduction}

Hospitalization rates among older adults account to more than one third of hospital admissions (1). Hospitalization in older adults is associated with poor health outcomes such as cognitive decline (2), as well as increased dependency in Activities of Daily Living (ADL) (3) and Instrumental Activities of Daily Living (IADL) (4), which in turn can lead to decreased autonomy and decreased quality of life and even increased mortality (5).

Low muscle strength and low muscle mass are diagnostic measures of sarcopenia and are prevalent in up to $45 \%$ of acutely hospitalized patients aged 65 years or older $(6,7)$. In community-dwelling older adults, low muscle strength and low muscle mass are associated with increased dependency in ADL (8), incident falls $(9,10)$ and mortality (11). Hospitalization frequently goes along with immobilization (5) and induces a decrease in muscle strength and muscle mass in electively admitted patients (12). Low muscle strength and low muscle mass could have prognostic value for poor health outcome after hospitalization and could possibly be a target for intervention in hospitalized patients (13). To the best of our knowledge, it is unknown whether muscle strength and/or muscle mass have prognostic value for dependency in (instrumental) activities of daily living after hospital discharge.

The aim of this study was to determine the association of muscle strength and muscle mass at admission with 1) ADL and IADL dependency at admission and 2) change in ADL and IADL dependency from admission to three months after discharge in hospitalized older patients aged 70 years and older.

\section{Methods}

\section{Study design}

The 'Evaluation of Muscle parameters in a Prospective cohort of Older patients at clinical Wards Exploring Relations with bed rest and malnutrition' (EMPOWER) study is an observational, prospective inception cohort study. A total of 838 subsequent hospitalized patients were screened for eligibility for inclusion from April 2015 to December 2015. Patients were included if they were aged 70 years and older and admitted to one of four clinical wards (acute admission, internal medicine, neurosurgery and orthopedics, traumatology) of the VU University Medical Center, Amsterdam, The Netherlands, a middle-sized teaching hospital. Patients were excluded if they were terminally ill, had an expected length of stay in the 


\section{THE JOURNAL OF NUTRITION, HEALTH \& AGING@}

hospital shorter than 24 hours, were admitted at another hospital and relocated to the VU University Medical Center, were nursed in isolation rooms or were not able to understand the Dutch language. The EMPOWER study included a total of 378 patients. Patients were assessed within 48 hours after hospital admission, comprising assessment of patient characteristics, measurements of muscle strength and muscle mass, and ADL and IADL dependency. ADL and IADL dependency was re-assessed at three months after discharge using telephone calls as described earlier (14). This study was reviewed and approved by the medical ethical committee of the VU University Medical Center, Amsterdam, The Netherlands. Informed consent was obtained from all included patients.

\section{Characteristics of patients}

At admission, the following items were assessed during an interview by a nurse: living situation, use of walking aid, risk of malnutrition defined by the Short Nutritional Assessment Questionnaire (SNAQ) score using a score $\geq 2$ out of 7 points (15), risk of delirium (16), cognitive impairment defined by the Six Item Cognitive Impairment Test (6CIT) score using a score $\geq 11$ out of 28 points (17).

The following items were collected from medical records: age, sex, multimorbidity, polypharmacy, acute or elective admission and length of stay. Multimorbidity was defined as two or more of the following diseases: cerebrovascular accident/transient ischemic attack, chronic obstructive pulmonary disease, hypertension, heart failure, chronic kidney disease, diabetes mellitus, malignancy, peripheral vascular disease, thyroid disease, Parkinson's disease, arthrosis, rheumatoid arthritis and osteoporosis. Polypharmacy was defined as five or more medications (18).

Weight was measured to the nearest 0.1 kilograms using a weighing chair. Self-reported weight was used when measurement of weight was impossible. Knee height was measured to the nearest 0.1 centimeter to estimate actual height to the nearest $1 \mathrm{~cm}$ using the Longitudinal Aging Study Amsterdam (LASA) formula (19). BMI was calculated to the nearest $0.1 \mathrm{kilogram} / \mathrm{meter}^{2}$ as weight divided by height squared.

\section{Handgrip strength}

HGS was measured using a hydraulic hand dynamometer (Jamar, Sammons Preston Rolyan, IL, USA). Measurements were performed according to instructions recommended by the American Society of Hand Therapists (20), i.e. patients were asked to sit straight up in a chair or on the edge of the bed, flex their elbow about 90 degrees, not support their elbows and squeeze maximally. If patients were unable to sit, patients were asked to put the bed in an angle of approximately 30 degrees, flex their elbow about 90 degrees, not support their elbows and squeeze maximally under verbal encouragement. Two measurements per hand side alternately were performed. The maximal value of all four measurements was used for analysis.

\section{Muscle mass}

Body composition was measured using direct segmental multi-frequency bioelectrical impedance analysis (DSM-BIA) (InBody S10, Biospace Co., Ltd, Seoul), which is a validated and standardized method of estimating skeletal muscle mass compared to DXA (21). Patients were asked to lie down in bed, spread their arms to about a 15 degrees' angle, arms not touching the trunk and to spread legs to shoulder width, thighs not touching each other. If patients were not able to lie down flat, measurements were performed in maximum supine position that could be reached. BIA measurements were not performed when the patient had a pacemaker or other implanted electronic device $(n=25)$ and when electrodes could not be placed on fingers or ankles $(n=21)$. The following measures of muscle mass were used for analyses: skeletal muscle mass (SMM) in kilograms, SMM as a percentage of total body weight (SMM\%) (8) and skeletal mass index as SMM divided by height squared (SMI) (22). Fat mass in kilograms was obtained during measurement of body composition and was measured to the nearest 0.1 kilograms.

\section{Activities of daily living and instrumental activities of daily living}

ADL dependency was assessed using the Katz score (23) ranging from 0 to 6 points, a lower score meaning greater dependency. For the cross-sectional analysis, ADL score was dichotomized: a score of $<6$ points was considered dependent and a score of 6 points was considered independent (24). IADL dependency was determined using the Lawton and Brody score (25) ranging from 0 to 8 points, a lower score meaning greater dependency. IADL score was dichotomized: a score of $<8$ points was considered dependent and a score of 8 points was considered independent (26). Due to a protocol amendment at a later stage in which the assessment of IADL was added to the protocol, IADL data at admission are available in sample of 262 $(69.3 \%)$ patients.

For longitudinal analysis, the change in ADL and IADL was defined as the score at follow-up assessment minus the score at admission (change in ADL and IADL); positive change ADL and IADL scores indicating a decrease in dependency and negative change in ADL or IADL scores indicating an increase in dependency.

\section{Statistical Analysis}

Continuous variables were presented as mean with standard deviation (SD) if normally distributed and as median with interquartile range (IQR) if not normally distributed.

Cross-sectional analysis of the associations of HGS, SMM, SMM\% and SMI (independent variables) with ADL and IADL dependency (dependent variables) at admission were analyzed using binary logistic regression analysis (independency $=1$, dependency $=0$ ). In model 1 , analyses were adjusted for age. In model 2 , analyses were additionally adjusted for multimorbidity and weight (kg) and height $(\mathrm{m})$ (for HGS) or fat mass $(\mathrm{kg})$ (for SMM and SMI) or weight (kg) (for SMM\%) (27). 


\section{MUSCLE MEASURES AND ACTIVITIES OF DAILY LIVING IN HOSPITALIZED OLDER ADULTS}

Longitudinal analyses of the association of HGS, SMM, SMM\% and SMI with the change in ADL and IADL scores were analyzed using linear regression analyses. In model 1 , analyses were adjusted for age and ADL or IADL score at admission. In model 2, analyses were additionally adjusted for multimorbidity and weight $(\mathrm{kg})$ and height $(\mathrm{m})$ (for HGS) or fat mass $(\mathrm{kg})$ (for SMM and SMI) or weight $(\mathrm{kg}$ ) (for SMM\%) (27).

Statistical analyses were performed using the Statistical Package for the Social Sciences, version 22 (IBM SPSS Statistics, IBM Corporation, Chicago, IL). P-values lower than 0.05 were considered statistically significant. P-values lower than 0.1 were considered a trend.

\section{Results}

Table 1 shows the patient characteristics at admission. The mean age of the total population was 79.7 years (SD 6.43) and $192(50.8 \%)$ patients were male. Most patients $(n=320,84.7 \%)$ were acutely admitted. HGS and muscle mass were lower in females compared to males. ADL and IADL dependency and scores at admission and three months post-discharge are shown in Table 2. ADL scores did not significantly change from admission to three months discharge. IADL scores were significantly lower at three months discharge compared to admission indicating relative increase of dependency in females and males.

Table 3 shows the cross-sectional analyses of the association of HGS and muscle mass with dependency in ADL and IADL at admission. Lower HGS was significantly associated with ADL dependency in both females and males. Lower SMM, SMM\% and SMI were significantly associated with ADL dependency in males, but not in females. Lower HGS was significantly associated with IADL dependency in males, but not in females. SMM, SMM\% and SMI were not associated with IADL.

Table 4 shows the association of HGS and muscle mass at admission with change in ADL and IADL scores between admission and three months after discharge. Lower HGS and SMM\% at admission were significantly associated with a decrease in ADL score indicating a relative increase of dependency in males, not in females. SMM and SMI were not associated with change in ADL score. Lower SMM and SMI showed a trend with a decrease in ADL scores in males. No association was found with change in IADL score.
Table 1

Patient characteristics at admission

\begin{tabular}{|c|c|c|c|}
\hline & $\mathbf{N}$ & $\begin{array}{c}\text { Females } \\
n=186\end{array}$ & $\begin{array}{l}\text { Males } \\
\mathrm{n}=192\end{array}$ \\
\hline Age, years & 378 & $80.3(6.54)$ & $79.1(6.23)$ \\
\hline Living independently, $\mathrm{n}(\%)$ & 373 & $161(89.0)$ & $178(92.7)$ \\
\hline Use of walking aid, $\mathrm{n}(\%)$ & 375 & $108(58.8)$ & $92(48.2)$ \\
\hline Risk of malnutrition ${ }^{\mathrm{a}}, \mathrm{n}(\%)$ & 367 & $56(30.8)$ & $68(36.0)$ \\
\hline Risk of delirium, $\mathrm{n}(\%)$ & 375 & $110(60.1)$ & $114(59.4)$ \\
\hline Cognitive impairment ${ }^{\mathrm{b}}, \mathrm{n}(\%)$ & 370 & $37(20.3)$ & $28(14.9)$ \\
\hline Multimorbidity $^{\mathrm{c}}, \mathrm{n}(\%)$ & 376 & $163(88.6)$ & $170(88.5)$ \\
\hline Polypharmacy $^{\mathrm{d}}, \mathrm{n}(\%)$ & 340 & $92(55.1)$ & $116(67.1)$ \\
\hline Acute admission, $\mathrm{n}(\%)$ & 378 & $153(82.3)$ & $167(87.0)$ \\
\hline Length of stay, median [IQR] & 377 & $5.13[3.05-8.77]$ & $4.88[2.69-7.34]$ \\
\hline Weight, $\mathrm{kg}$ & 378 & $68.7(18.3)$ & $77.4(14.6)$ \\
\hline Height $^{\mathrm{e}}, \mathrm{cm}$ & 378 & $162(6.27)$ & $175(6.85)$ \\
\hline $\mathrm{BMI}, \mathrm{kg} / \mathrm{m}^{2}$ & 378 & $26.4(6.82)$ & $25.2(4.41)$ \\
\hline Fat mass, $\mathrm{kg}$ & 321 & $25.7(12.5)$ & $21.7(9.49)$ \\
\hline HGS, $\mathrm{kg}$ & 378 & $14.9(5.65)$ & $26.1(9.84)$ \\
\hline SMM, kg & 321 & $22.5(3.76)$ & $29.8(5.62)$ \\
\hline SMM $\%, \%$ & 321 & $33.7(5.66)$ & $39.1(5.00)$ \\
\hline $\mathrm{SMI}, \mathrm{kg} / \mathrm{m}^{2}$ & 321 & $8.64(1.24)$ & $9.70(1.48)$ \\
\hline
\end{tabular}

All variables are presented as mean (SD), unless otherwise indicated. IQR: interquartile range, BMI: body mass index, HGS: handgrip strength, SMM: skeletal muscle mass, SMI: skeletal muscle mass index. ${ }^{\text {a }}$ Short Nutritional Assessment Questionnaire score $\geq 2$. ${ }^{\mathrm{b}}$ Six Item Cognitive Impairment Test $\geq 11 .{ }^{\mathrm{c}}$ Number of medications $\geq 5$. ${ }^{\mathrm{d}}$ Number of comorbidities $\geq 2 .{ }^{\circ}$ Based on knee height and LASA formula.

\section{Discussion}

In an observational prospective inception cohort study of hospitalized patients aged 70 years and older lower hand grip strength (HGS) was associated with ADL dependency at admission. Muscle mass, i.e. relative and absolute skeletal muscle mass and skeletal muscle mass index were associated with ADL at admission, but in males only. Both lower HGS and relative skeletal mass were associated with an increase of ADL dependency at three months after discharge, but only in males. Only HGS at admission was associated with IADL at admission and only in males.

HGS was consistently associated with ADL dependency. HGS values in our population were similar to sarcopenic community dwelling subjects and acutely hospitalized subjects $(28,29)$ and lower compared to geriatric outpatients (27). HGS in female patients was comparable to much older individuals of the general population (aged 89 years and older) (30) and chronically ill patients (31). Values of muscle mass measures similar to community dwelling older subjects (32) and geriatric outpatients (33). 
THE JOURNAL OF NUTRITION, HEALTH \& AGINGC

Table 2

Activities of daily living and instrumental activities of daily living at admission and three months post-discharge

\begin{tabular}{|c|c|c|c|c|c|c|c|c|}
\hline & \multicolumn{3}{|c|}{ Admission } & \multicolumn{3}{|c|}{ Three months post-discharge } & \multicolumn{2}{|c|}{ Change } \\
\hline & $\mathbf{N}$ & $\begin{array}{l}\text { Dependency, } \\
\text { n (\%) }\end{array}$ & $\begin{array}{c}\text { Score, } \\
\text { median [IQR] }\end{array}$ & $\mathbf{N}$ & $\begin{array}{c}\text { Dependency, } \\
\text { n }(\%) \\
\end{array}$ & $\begin{array}{c}\text { Score, } \\
\text { median [IQR] }\end{array}$ & $\mathbf{N}$ & $\begin{array}{c}\text { Score, } \\
\text { mean }(\mathrm{SD})\end{array}$ \\
\hline \multicolumn{9}{|l|}{$A D L$} \\
\hline Females & 181 & $97(53.6)$ & $5[3-6]$ & 151 & 87 (57.6) & $5[4-6]$ & 149 & $0.21(1.78)$ \\
\hline Males & 192 & $91(47.4)$ & $6[3-6]$ & 140 & $64(45.7)$ & $6[4-6]$ & 140 & $0.16(1.69)$ \\
\hline \multicolumn{9}{|l|}{$I A D L$} \\
\hline Females & 131 & $77(58.8)$ & $7[4-8]$ & 148 & $110(74.3)$ & $6[3-8]$ & 102 & $-0.75(2.00) *$ \\
\hline Males & 131 & $100(76.3)$ & $6[3-7]$ & 135 & $108(80.0)$ & $6[3-7]$ & 95 & $-0.44(1.96)^{*}$ \\
\hline
\end{tabular}

IQR: interquartile range, SD: standard deviation, ADL: activities of daily living, IADL: instrumental activities of daily living. *Statistically significant.

Table 3

Association of muscle measures with dependency in Activities of Daily Living and Instrumental Activities of Daily Living at admission, stratified for sex

\begin{tabular}{|c|c|c|c|c|c|c|c|}
\hline & & \multicolumn{3}{|c|}{ ADL dependency } & \multicolumn{3}{|c|}{ IADL dependency } \\
\hline & & $\mathbf{N}$ & OR (95\% C.I.) & P-value & $\mathbf{N}$ & OR (95\% C.I.) & P-value \\
\hline \multicolumn{8}{|l|}{ Females } \\
\hline \multirow[t]{2}{*}{$\mathrm{HGS}, \mathrm{kg}$} & Model 1 & 157 & $0.92(0.86-0.98)$ & 0.015 & 111 & $0.95(0.87-1.04)$ & 0.290 \\
\hline & Model 2 & & $0.90(0.83-0.96)$ & 0.003 & & $0.93(0.84-1.02)$ & 0.126 \\
\hline \multirow[t]{2}{*}{$\mathrm{SMM}, \mathrm{kg}$} & Model 1 & 157 & $1.05(0.96-1.15)$ & 0.284 & 111 & $1.02(0.91-1.14)$ & 0.725 \\
\hline & Model 2 & & $1.01(0.92-1.11)$ & 0.833 & & $0.97(0.86-1.10)$ & 0.644 \\
\hline \multirow[t]{2}{*}{ SMM, \% } & Model 1 & 157 & $0.95(0.90-1.01)$ & 0.096 & 111 & $0.96(0.90-1.03)$ & 0.288 \\
\hline & Model 2 & & $1.00(0.92-1.08)$ & 0.915 & & $0.98(0.89-1.08)$ & 0.710 \\
\hline \multirow[t]{2}{*}{$\mathrm{SMI}, \mathrm{kg} / \mathrm{m}^{2}$} & Model 1 & 157 & $1.17(0.90-1.53)$ & 0.246 & 111 & $1.06(0.77-1.45)$ & 0.723 \\
\hline & Model 2 & & $1.01(0.75-1.37)$ & 0.925 & & $0.89(0.62-1.28)$ & 0.529 \\
\hline \multicolumn{8}{|l|}{ Males } \\
\hline \multirow[t]{2}{*}{$\mathrm{HGS}, \mathrm{kg}$} & Model 1 & 158 & $0.93(0.89-0.97)$ & 0.001 & 112 & $0.94(0.89-0.99)$ & 0.023 \\
\hline & Model 2 & & $0.94(0.90-0.98)$ & 0.007 & & $0.94(0.89-1.00)$ & 0.057 \\
\hline \multirow[t]{2}{*}{ SMM, kg } & Model 1 & 158 & $0.86(0.79-0.93)$ & $<0.001$ & 112 & $0.95(0.88-1.03)$ & 0.193 \\
\hline & Model 2 & & $0.86(0.80-0.94)$ & $<0.001$ & & $0.96(0.88-1.04)$ & 0.303 \\
\hline \multirow[t]{2}{*}{ SMM, \% } & Model 1 & 158 & $0.93(0.87-1.00)$ & 0.040 & 112 & $0.98(0.90-1.08)$ & 0.706 \\
\hline & Model 2 & & $0.87(0.80-0.95)$ & 0.002 & & $0.96(0.87-1.07)$ & 0.492 \\
\hline \multirow[t]{2}{*}{$\mathrm{SMI}, \mathrm{kg} / \mathrm{m}^{2}$} & Model 1 & 158 & $0.60(0.46-0.79)$ & $<0.001$ & 112 & $0.82(0.60-1.11)$ & 0.196 \\
\hline & Model 2 & & $0.61(0.46-0.80)$ & $<0.001$ & & $0.85(0.61-1.18)$ & 0.338 \\
\hline
\end{tabular}

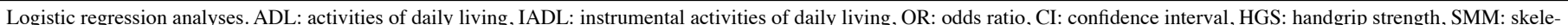
tal muscle mass, SMI: skeletal muscle index. Model 1: adjustment for age. Model 2: model 1 and multimorbidity and, weight and height (for HGS), or fat mass (for SMM and SMI), or weight (for SMM\%). Bold values are statistically significant.

Associations of muscle measures with ADL dependency are in line with previous findings in community dwelling older adults $(26,34,35)$. Other studies have found muscle strength to be associated with both ADL and IADL (36). Our study showed only a trend for handgrip strength and IADL in males. Stronger associations of muscle measures with ADL might be explained by the fact that Katz ADL and Lawton and Brody
IADL score cover different domains of ADL (37): the Katz ADL involves basic ADL functions and IADL encompasses more complex tasks in which cognition plays a more dominant role (38-40). Muscle mass, as an obvious contributing factor to muscle strength (41) was found to be relatively preserved in the present cohort and associated with ADL in males only. Results are in line with the notion that muscle strength may be 
Table 4

Association of muscle measures at admission with change in activities of daily living and instrumental activities of daily living scores, stratified by sex

\begin{tabular}{|c|c|c|c|c|c|c|c|}
\hline & & \multicolumn{3}{|c|}{ Change in ADL score } & \multicolumn{3}{|c|}{ Change in IADL score } \\
\hline & & $\mathbf{N}$ & $\beta$ (95\% C.I.) & P-value & $\mathbf{N}$ & $\beta$ (95\% C.I.) & P-value \\
\hline \multicolumn{8}{|l|}{ Females } \\
\hline \multirow[t]{2}{*}{ HGS, kg } & Model 1 & 125 & $0.03(-0.03-0.08)$ & 0.320 & 83 & $0.00(-0.09-0.10)$ & 0.952 \\
\hline & Model 2 & & $0.04(-0.01-0.09)$ & 0.144 & & $-0.01(-0.12-0.09)$ & 0.832 \\
\hline \multirow[t]{2}{*}{ SMM, kg } & Model 1 & 125 & $-0.01(-0.07-0.05)$ & 0.739 & 83 & $0.06(-0.06-0.17)$ & 0.335 \\
\hline & Model 2 & & $0.00(-0.07-0.07)$ & 0.933 & & $0.07(-0.05-0.20)$ & 0.235 \\
\hline \multirow[t]{2}{*}{ SMM, \% } & Model 1 & 125 & $0.01(-0.04-0.05)$ & 0.821 & 83 & $0.05(-0.03-0.13)$ & 0.191 \\
\hline & Model 2 & & $-0.01(-0.07-0.04)$ & 0.673 & & $0.07(-0.03-0.17)$ & 0.161 \\
\hline \multirow[t]{2}{*}{$\mathrm{SMI}, \mathrm{kg} / \mathrm{m}^{2}$} & Model 1 & 125 & $0.00(-0.19-0.20)$ & 0.980 & 83 & $0.14(-0.21-0.49)$ & 0.437 \\
\hline & Model 2 & & $0.05(-0.17-0.27)$ & 0.669 & & $0.22(-0.17-0.61)$ & 0.266 \\
\hline \multicolumn{8}{|l|}{ Males } \\
\hline \multirow[t]{2}{*}{ HGS, kg } & Model 1 & 116 & $0.03(0.00-0.06)$ & 0.027 & 79 & $0.01(-0.04-0.06)$ & 0.675 \\
\hline & Model 2 & & $0.03(0.00-0.06)$ & 0.021 & & $0.01(-0.05-0.06)$ & 0.851 \\
\hline \multirow[t]{2}{*}{$\mathrm{SMM}, \mathrm{kg}$} & Model 1 & 116 & $0.04(-0.01-0.08)$ & 0.093 & 79 & $0.05(-0.03-0.12)$ & 0.210 \\
\hline & Model 2 & & $0.04(-0.01-0.08)$ & 0.087 & & $0.05(-0.03-0.12)$ & 0.228 \\
\hline \multirow[t]{2}{*}{ SMM, \% } & Model 1 & 116 & $0.05(0.00-0.09)$ & 0.030 & 79 & $0.01(-0.07-0.08)$ & 0.894 \\
\hline & Model 2 & & $0.06(0.01-0.11)$ & 0.020 & & $0.03(-0.06-0.11)$ & 0.513 \\
\hline \multirow[t]{2}{*}{ SMI, $\mathrm{kg} / \mathrm{m}^{2}$} & Model 1 & 116 & $0.16(-0.02-0.33)$ & 0.078 & 79 & $0.22(-0.09-0.53)$ & 0.169 \\
\hline & Model 2 & & $0.17(0.00-0.35)$ & 0.053 & & $0.21(-0.11-0.52)$ & 0.192 \\
\hline
\end{tabular}

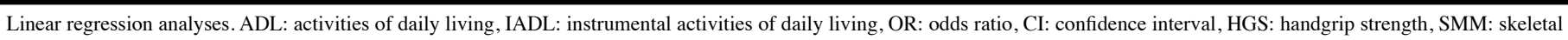

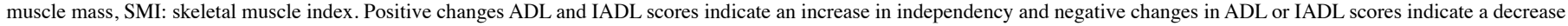

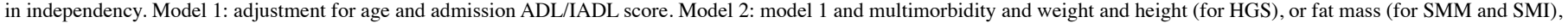
or weight (for SMM\%). Bold values are statistically significant.

influenced by other factors than muscle quantity alone (42) and that muscle mass and muscle strength are different constructs (43), which relate to clinical outcomes in different ways (44, 45). An apparent sex- specificity in this respect requires further attention.

In the present study, a significant decline three months after admission was found for the IADL scores, implying that IADL is more sensitive to change than basic ADL activities after hospital discharge in older patients (37).

In a previous cohort study of 492 older hospitalized subjects, $54 \%$ was found to be independent in ADL before admission and $44 \% 3$ months after admission (46). One third of the patients suffered a functional decline defined of at least one point loss on the Katz score three months after discharge. A decline in independency after hospitalization is further substantiated by a previous study in which most patients became more dependent after hospital admission and some did not return to their pre-hospitalization dependency (46). The question whether hospitalization by itself is a risk factor for ALD decline is difficult to answer without comparison to trajectories of ADL decline in similar but not hospitalized subjects. In a previous study, muscle measures were not found to change during hospitalization (47) although immobilization during hospital stay was found to have acute negative impact on muscle mass and strength (48), which might be further substantiated after discharge.

\section{Strength and limitations}

EMPOWER is a large prospective inception cohort study of older adults admitted to various specialisms minimizing selection bias and ensuring diversity, representative for an older hospital population. Muscle mass parameters were measured by use of portable BIA devices, which is susceptible to hydration state which was as much as possible controlled for. Patients who were expected to be discharged within 24 hours of admission were not included due to the short stay, which could have caused selection bias excluding the healthier patients. The used ADL and IADL scales have ceiling effects reducing sensitivity for changes and potentially interfering with addressed associations. 


\section{THE JOURNAL OF NUTRITION, HEALTH \& AGINGC}

\section{Conclusion}

Muscle measures at hospital admission in older patients are related to ADL dependency at admission and change in ADL dependency three months after discharge, however, these associations are sex specific. Taken aforementioned findings into account, HGS may be useful to predict outcome after hospital admission. Further research into trajectories of ADL dependency, before, during and after hospitalization are required to further pinpoint risk factors, patients at risk and identification and allocation of preventive measures.

\section{Conflict of Interest: None of the authors report a conflict of interest.}

Funding: This study was supported by the seventh framework program MYOAGE (HEALTH-2007-2.4.5-10); European Union's Horizon 2020 research and innovation programme (No 689238 and No 675003); and Nutricia Research, Nutricia Advanced Medical Nutrition, The Netherlands.

Ethical Standards: This study was reviewed and approved by the medical ethica committee of the VU University Medical Center, Amsterdam, The Netherlands. Informed consent was obtained from all included patients.

Open Access: This article is distributed under the terms of the Creative Commons Attribution 4.0 International License (http://creativecommons.org/licenses/by/4.0/), which permits use, duplication, adaptation, distribution and reproduction in any medium or format, as long as you give appropriate credit to the original author(s) and the source, provide a link to the Creative Commons license and indicate if changes were made.

\section{References}

1. Reed RL, Isherwood L, Ben-Tovim D. Why do older people with multi-morbidity experience unplanned hospital admissions from the community: a root cause analysis. BMC Health Serv Res 2015;15:525

2. Ehlenbach WJ, Hough CL, Crane PK, Haneuse SJ, Carson SS, Curtis JR, et al. Association between acute care and critical illness hospitalization and cognitive function in older adults. JAMA 2010;303(8):763-70

3. Covinsky KE, Palmer RM, Fortinsky RH, Counsell SR, Stewart AL, Kresevic D, et al. Loss of independence in activities of daily living in older adults hospitalized with medical illnesses: increased vulnerability with age. J Am Geriatr Soc 2003;51(4):451-8

4. Sager MA, Franke T, Inouye SK, Landefeld CS, Morgan TM, Rudberg MA, et al. Functional outcomes of acute medical illness and hospitalization in older persons. Arch Intern Med 1996;156(6):645-52

5. Creditor MC. Hazards of hospitalization of the elderly. Ann Intern Med 1993;118(3):219-23

6. Cerri AP, Bellelli G, Mazzone A, Pittella F, Landi F, Zambon A, et al. Sarcopenia and malnutrition in acutely ill hospitalized elderly: Prevalence and outcomes. Clin Nutr 2015;34(4):745-51

7. Matos LC, Tavares MM, Amaral TF. Handgrip strength as a hospital admission nutritional risk screening method. Eur J Clin Nutr 2007;61(9):1128-35

8. Janssen I, Heymsfield SB, Ross R. Low relative skeletal muscle mass (sarcopenia) in older persons is associated with functional impairment and physical disability. J Am Geriatr Soc 2002;50(5):889-96

9. Landi F, Liperoti R, Russo A, Giovannini S, Tosato M, Capoluongo E, et al Sarcopenia as a risk factor for falls in elderly individuals: results from the ilSIRENTE study. Clin Nutr 2012:31(5):652-8

10. Van Ancum JM, Pijnappels M, Jonkman NH, Scheerman K, Verlaan S, Meskers CGM, et al. Muscle mass and muscle strength are associated with pre- and posthospitalization falls in older male inpatients: a longitudinal cohort study. BMC Geriatr 2018;18(1):116

11. Metter EJ, Talbot LA, Schrager M, Conwit R. Skeletal muscle strength as a predictor of all-cause mortality in healthy men. J Gerontol A Biol Sci Med Sci 2002;57(10):B359-65

12. Van Ancum JM, Scheerman K, Jonkman NH, Smeenk HE, Kruizinga RC, Meskers CGM, et al. Change in muscle strength and muscle mass in older hospitalized patients: A systematic review and meta-analysis. Exp Gerontol 2017;92:34-41

13. Bosaeus I, Rothenberg E. Nutrition and physical activity for the prevention and treatment of age-related sarcopenia. Proc Nutr Soc 2016;75(2):174-80

14. Verlaan S, Van Ancum J, Pierik VD, Van JW, Scheerman K, Meskers CG, et al Muscle Measures and Nutritional Status at Hospital Admission Predict Surviva and Independent Living of Older Patients-the EMPOWER Study. J Frailty Aging 2017;6(3):161-6

15. Kruizenga HM, Seidell JC, de Vet HC, Wierdsma NJ, van Bokhorst-de van der Schueren MA. Development and validation of a hospital screening tool for malnutrition: the short nutritional assessment questionnaire (SNAQ). Clin Nut 2005;24(1):75-82

16. Oud FM, de Rooij SE, Schuurman T, Duijvelaar KM, van Munster BC. [Predictive value of the VMS theme 'Frail elderly': delirium, falling and mortality in elderly hospital patients]. Ned Tijdschr Geneeskd 2015;159:A8491

17. Upadhyaya AK, Rajagopal M, Gale TM. The Six Item Cognitive Impairment Test (6-CIT) as a screening test for dementia: comparison with Mini-Mental State Examination (MMSE). Curr Aging Sci 2010;3(2):138-42

18. Hajjar ER, Cafiero AC, Hanlon JT. Polypharmacy in elderly patients. Am J Geriatr Pharmacother 2007;5(4):345-51

19. Chumlea WC, Roche AF, Steinbaugh ML. Estimating stature from knee height for persons 60 to 90 years of age. J Am Geriatr Soc 1985;33(2):116-20

20. Fess EE. The need for reliability and validity in hand assessment instruments. J Hand Surg Am 1986;11(5):621-3

21. Ling $\mathrm{CH}$, de Craen AJ, Slagboom PE, Gunn DA, Stokkel MP, Westendorp RG et al. Accuracy of direct segmental multi-frequency bioimpedance analysis in the assessment of total body and segmental body composition in middle-aged adult population. Clin Nutr 2011;30(5):610-5

22. Janssen I, Baumgartner RN, Ross R, Rosenberg IH, Roubenoff R. Skeletal muscle cutpoints associated with elevated physical disability risk in older men and women. Am J Epidemiol 2004;159(4):413-21

23. Katz S, Ford AB, Moskowitz RW, Jackson BA, Jaffe MW. Studies of Illness in the Aged. The Index of Adl: A Standardized Measure of Biological and Psychosocial Function. JAMA 1963;185:914-9

24. Millan-Calenti JC, Tubio J, Pita-Fernandez S, Gonzalez-Abraldes I, Lorenzo T, Fernandez-Arruty T, et al. Prevalence of functional disability in activities of daily living (ADL), instrumental activities of daily living (IADL) and associated factors, as predictors of morbidity and mortality. Arch Gerontol Geriatr 2010;50(3):306-10

25. Lawton MP, Brody EM. Assessment of older people: self-maintaining and instrumental activities of daily living. Gerontologist 1969;9(3):179-86

26. Gonzalez-Zabaleta J, Pita-Fernandez S, Seoane-Pillado T, Lopez-Calvino B, Gonzalez-Zabaleta JL. Dependence for basic and instrumental activities of daily living after hip fractures. Arch Gerontol Geriatr 2015;60(1):66-70

27. Reijnierse EM, Trappenburg MC, Leter MJ, Blauw GJ, de van der Schueren MA, Meskers CG, et al. The Association between Parameters of Malnutrition and Diagnostic Measures of Sarcopenia in Geriatric Outpatients. PLoS One 2015;10(8):e0135933

28. Bauer JM, Verlaan S, Bautmans I, Brandt K, Donini LM, Maggio M, et al. Effects of a vitamin $\mathrm{D}$ and leucine-enriched whey protein nutritional supplement on measures of sarcopenia in older adults, the PROVIDE study: a randomized, double-blind, placebocontrolled trial. J Am Med Dir Assoc 2015;16(9):740-7

29. De Buyser SL, Petrovic M, Taes YE, Vetrano DL, Corsonello A, Volpato S, et al Functional changes during hospital stay in older patients admitted to an acute care ward: a multicenter observational study. PLoS One 2014;9(5):e96398

30. Ling CH, Taekema D, de Craen AJ, Gussekloo J, Westendorp RG, Maier AB. Handgrip strength and mortality in the oldest old population: the Leiden 85-plus study CMAJ 2010;182(5):429-35

31. Beenakker KG, Ling CH, Meskers CG, de Craen AJ, Stijnen T, Westendorp RG, et al Patterns of muscle strength loss with age in the general population and patients with a chronic inflammatory state. Ageing Res Rev 2010;9(4):431-6

32. Rojer AGM, Reijnierse EM, Trappenburg MC, van Lummel RC, Niessen M, van Schooten KS, et al. Instrumented Assessment of Physical Activity Is Associated With Muscle Function but Not With Muscle Mass in a General Population. J Aging Health, 2017;898264317721554

33. Reijnierse EM, Trappenburg MC, Leter MJ, Blauw GJ, Sipila S, Sillanpaa E, et al. The Impact of Different Diagnostic Criteria on the Prevalence of Sarcopenia in Healthy Elderly Participants and Geriatric Outpatients. Gerontology 2015;61(6):491-6

34. Hairi NN, Cumming RG, Naganathan V, Handelsman DJ, Le Couteur DG, Creasey H, et al. Loss of muscle strength, mass (sarcopenia), and quality (specific force) and it relationship with functional limitation and physical disability: the Concord Health and Ageing in Men Project. J Am Geriatr Soc 2010;58(11):2055-62

35. Davis JW, Ross PD, Preston SD, Nevitt MC, Wasnich RD. Strength, physica activity, and body mass index: relationship to performance-based measures and activities of daily living among older Japanese women in Hawaii. J Am Geriatr Soc 1998;46(3):274-9

36. Benjumea AM, Curcio CL, Duque G, Gomez F. Dynapenia and Sarcopenia as a Risk Factor for Disability in a Falls and Fractures Clinic in Older Persons. Open Access Maced J Med Sci 2018;6(2):344-9

37. Suijker JJ, van Rijn M, Ter Riet G, Moll van Charante EP, de Rooij SE, Buurman BM. Minimal Important Change and Minimal Detectable Change in Activities of Daily Living in Community-Living Older People. J Nutr Health Aging 2017;21(2):165-72

38. McGuire LC, Ford ES, Ajani UA. Cognitive functioning as a predictor of functional disability in later life. Am J Geriatr Psychiatry 2006;14(1):36-42

39. Gold DA. An examination of instrumental activities of daily living assessment in older adults and mild cognitive impairment. J Clin Exp Neuropsychol 2012;34(1):11-34

40. Amanzio M, Palermo S, Zucca M, Rosato R, Rubino E, Leotta D, et al Neuropsychological correlates of instrumental activities of daily living in neurocognitive disorders: a possible role for executive dysfunction and mood changes. Int Psychogeriatr 2018;1-11

41. Newman AB, Haggerty CL, Goodpaster B, Harris T, Kritchevsky S, Nevitt M, et al Strength and muscle quality in a well-functioning cohort of older adults: the Health, 


\section{MUSCLE MEASURES AND ACTIVITIES OF DAILY LIVING IN HOSPITALIZED OLDER ADULTS}

Aging and Body Composition Study. J Am Geriatr Soc 2003;51(3):323-30

42. Goodpaster BH, Carlson CL, Visser M, Kelley DE, Scherzinger A, Harris TB, et al. Attenuation of skeletal muscle and strength in the elderly: The Health ABC Study. J Appl Physiol 2001;90(6):2157-65

43. Pendleton HM, Schultz-Krohn W. Pedretti's Occupational Therapy-E-Book: Practice Skills for Physical Dysfunction: Elsevier Health Sciences 2017;159 p.

44. Bijlsma AY, Meskers CG, Ling CH, Narici M, Kurrle SE, Cameron ID, et al. Defining sarcopenia: the impact of different diagnostic criteria on the prevalence of sarcopenia in a large middle aged cohort. Age (Dordr) 2013;35(3):871-81

45. Bijlsma AY, Pasma JH, Lambers D, Stijntjes M, Blauw GJ, Meskers CG, et al Muscle strength rather than muscle mass is associated with standing balance in elderly outpatients. J Am Med Dir Assoc 2013;14(7):493-8

46. Hoogerduijn JG, Buurman BM, Korevaar JC, Grobbee DE, de Rooij SE, Schuurmans MJ. The prediction of functional decline in older hospitalised patients. Age Ageing 2012;41(3):381-7

47. Van Ancum JM, Scheerman K, Pierik VD, Numans ST, Verlaan S, Smeenk HE, et al. Muscle Strength and Muscle Mass in Older Patients during Hospitalization: The EMPOWER Study. Gerontology 2017;63(6):507-14

48. Kortebein P, Symons TB, Ferrando A, Paddon-Jones D, Ronsen O, Protas E, et al. Functional impact of 10 days of bed rest in healthy older adults. J Gerontol A Biol Sci Med Sci 2008;63(10):1076-81 